\title{
Genetic analysis of the human hair roots as a tool for spaceflight experiments"
}

\author{
Masahiro Terada ${ }^{1 \#}$, Masaya Seki $^{2}$, Akira Higashibata $^{1}$, Shin Yamada $^{1}$, Rika Takahashi $^{2}$, \\ Hideyuki J. Majima ${ }^{3}$, Takashi Yamazaki ${ }^{1}$, Tomomi Watanabe-Asaka ${ }^{1}$, Maki Niihori ${ }^{1}$, Chiaki Mukai ${ }^{1}$, \\ Noriaki Ishioka ${ }^{1}$ \\ ${ }^{1}$ Japan Aerospace Exploration Agency, Tsukuba City, Japan \\ ${ }^{2}$ Advanced Engineering Services Co., Ltd., Tsukuba City, Japan \\ ${ }^{3}$ Graduate School of Medical and Dental Sciences, Kagoshima University, Kagoshima City, Japan \\ Email: ${ }_{\text {terada.masahiro@jaxa.jp }}$
}

Received 5 August 2013; revised 5 September 2013; accepted 5 October 2013

Copyright (C) 2013 Masahiro Terada et al. This is an open access article distributed under the Creative Commons Attribution License, which permits unrestricted use, distribution, and reproduction in any medium, provided the original work is properly cited.

\begin{abstract}
The use of hair roots as experimental samples has been a research focus for understanding the effects of spaceflight on astronauts, because it has many advantages, one of which is the fact that hair matrix cells actively divide in a hair follicle and sensitively reflect the physical conditions of the human body. In 2009, a research program focusing on the analysis of astronauts' hairs was initiated to examine the effects of long-term spaceflight on the gene expression and mineral metabolism in the human body. Since the number of samples per astronaut is limited to 5 strands of hairs at each sampling point, due to the ethical viewpoint of astronauts or limited resources in space, it is important to develop an effective method for the molecular analysis of small amounts of hair roots. In this study, mRNA successfully extracted from 1,5 , and 10 hair follicles was amplified and subjected to the DNA microarray analysis to compare the gene expression within subjects. The results indicated that (1) it was possible to perform the genetic analysis on hair samples stored at $-80^{\circ} \mathrm{C}$, even without a fixation buffer and (2) the newly modified method of mRNA extraction and analysis was effective in detecting differential gene expression in samples containing only 5 hairs. In conclusion, RNA was efficiently extracted from 5 hair roots, which is the same number of hair roots used in the space experiment; therefore, this method can be applied to genetically analyze astronauts' hair samples.
\end{abstract}

\footnotetext{
"Conflict of interest: The authors declare that there is no conflict of interest.

"Corresponding author.
}

Keywords: Hair Root; Microarray; Space; Astronaut; RNA; Gene Expression

\section{INTRODUCTION}

Examination of the human hair serves as an effective tool for determining stress levels and metabolic conditions in the human body in response to the microgravity environment and cosmic radiation. In December 2009, the Japan Aerospace Exploration Agency (JAXA) initiated the "HAIR" research program to analyze the properties of and changes in astronauts' hair during spaceflight [1], the purpose of which is to elucidate the effects of long-term exposure to spaceflight on the gene expression and mineral metabolism in human hair. In the frame of the "HAIR" experiment, 10 astronauts from the International Space Station (ISS) crews will be subjected to hair sampling and analysis. Such an experiment will be the first to examine the fine clear effect of long-term exposure to spaceflight on exodermal tissues.

Hair matrix cells actively divide in a hair follicle [2,3] and are known to sensitively reflect the host's physical conditions [4-6]. Akashi et al. [2010] reported that the circadian phase of clock gene expression in hair follicle cells corresponds to that of individual behavioral rhythms and therefore is effective for evaluating the properties of the human peripheral circadian clock. In addition, the hair shaft has also been shown to record the metabolic changes in the organism in response to changing environments [7,8]. For example, high levels of toxic metals, such as mercury, cadmium, arsenic, and lead, have been observed in the hair of people exposed to toxic metal pollution [9]. The hair mineral analysis has also been widely used for forensic science, the assessment of envi- 
ronmental exposure [10-13], the evaluation of nutritional statuses, and disease diagnosis $[14,15]$. It was previously reported that 14 days of hindlimb suspension (a simulated microgravity model of skeletal muscle) led to changes in the levels of 26 minerals in rat body hair [1], supporting that hair samples would be an informative tool for examining the effect of spaceflight on humans, especially taking into account that no special complex hardware and handling are required for hair collection.

In the frame of the "HAIR" experiment, both hair roots and hair shafts collected from the ISS crews are subjected to the analysis. It is known that the expression of immunoglobulin heavy-chain mRNA in the amphibian Pleurodeles walt changes during spaceflight [16]. Spaceflight has also been shown to cause gene expression changes in rat and mouse skeletal muscles [17-19]. In addition, studies have suggested that spaceflight affects the organization of microtubules and mitochondria, thereby resulting in increased apoptosis [20]. Therefore, along with the analysis of hair roots, nucleic acids (RNA and mitochondrial DNA) will be extracted from the collected hair roots and subjected to the analysis of gene expression changes during spaceflight. The extracted total RNA will be analyzed by the DNA microarray technique, and the effects of spaceflight on the expression levels of stressrelated genes, such as oxidative stress gene networks, will be further examined. In addition, the multiple effects of microgravity and cosmic radiation on the copy number of mitochondrial DNA will also be investigated. Moreover, immune system-related genes will be analyzed using a human immunological cDNA chip. Furthermore, to examine trace element metabolism in the human body, the contents of minerals (e.g., Na, K, and Ca) and trace elements (e.g., mercury) in the hair shaft of ISS crews will be analyzed using an electron probe microanalyzer.

However, in the "HAIR" experiment, the number of hair samples is limited to only 5 strands from each astronaut, due to the ethical viewpoint of astronauts or limited resources in space. Therefore, it is essential to develop a method to effectively analyze the gene expression with a limited number of hair roots. To achieve this purpose, in the current study, the microarray analysis was performed using RNA extracted from 1, 5, or 10 hair roots.

\section{MATERIALS AND METHODS}

\subsection{Hair Sample Preparation}

One, 5, and 10 strands of hair were taken several times from each of 2 healthy voluntary male subjects (age, 33 36 years). Individual hairs were grasped as near to the scalp as possible and pulled out by pulling several times with tweezers in the direction of hair growth without damaging hair roots. Samples were stored at $-80^{\circ} \mathrm{C}$ until analysis. Similar biological conditions for material storage will be employed for the HAIR experiment during spaceflight. This study was approved by the Committee on Human Care and Use at the JAXA Institutional Review Board. All the participants provided written informed consent.

\subsection{RNA Extraction}

Hair roots (approximately $2-3 \mathrm{~mm}$ ) were used as the sources for mRNA extraction and were cut into about 15 fragments $(0.1-0.2 \mathrm{~mm}$ each) using a microsurgical knife under a stereoscopic microscope. Collected fragments were immersed in $800 \mu \mathrm{l}$ of ISOGEN Reagent (Nippon Gene, Toyama, Japan) in tubes and stirred (15 s $\times 2$ times) using the sonication device, Bioruptor UCD250 (Cosmo Bio, Tokyo, Japan). Next, RNA was purified from hair lysates with the ISOGEN Kit as described previously [21]. Briefly, tubes were kept at room temperature for $5 \mathrm{~min}$, followed by addition of $200 \mu \mathrm{l}$ of chloroform. Subsequent processes of RNA purification were performed according to the manufacturer's instructions. After isolation, RNA pellets were washed with $70 \%$ ethanol, air dried, and resuspended in $10 \mu \mathrm{l}$ of RNA-free water (Gibco-BRL, Gaithersburg, MD). Total RNA was quantified at $260 \mathrm{~nm}$ using the NanoDrop ND-1000 spectrophotometer (NanoDrop Technologies Inc., Wilmington, DE). The RNA quality was determined using the Agilent Bioanalyzer 2100 (Agilent Technologies, Palo Alto, CA). The 28S:18S rRNA ratio and the RNA integrity number (RIN) were calculated with the 2100 Expert software and the RIN Beta Version software (Agilent Technologies), respectively. RIN was calculated by allowing the classification of total RNA, based on a numbering system from 1 (most degraded) to 10 (most intact) $[22,23]$.

\subsection{RNA Amplification}

Due to the small amount of RNA extracted from hair samples, a double RNA amplification step was incorporated prior to microarray hybridization. Total RNA was amplified using the Ambion MessageAmp aRNA Kit as described previously [24]. Briefly, first- and secondstrand cDNA was synthesized. Unlabeled aRNA was generated by in vitro transcription with unbiotinylated NTPs. For probe preparation, aRNA was reverse transcribed with second-round primers. The second-strand cDNA was synthesized with the T7 oligo (dT) primer and purified. Biotin-labeled cRNA was generated by in vitro transcription and then purified with the RNeasy Kit (Qiagen, Venlo, The Netherlands). 


\subsection{Generation and Mining of Microarray Data}

Amplified RNA was processed and hybridized to the Whole Human Genome $(8 \times 60 \mathrm{~K})$ Oligo Microarray (Agilent Technologies), according to the manufacturer's protocol. Slide scanning was performed using the Agilent DNA Microarray Scanner (Agilent Technologies) by DNA Chip Research Inc. (Yokohama, Japan). Expression profiles were collected in triplicate at each time point, and scanning data were normalized with Agilent's Feature Extraction software (Agilent Technologies). Data preprocessing and analysis were performed using the GeneSpring software 11.0.1 (Agilent Technologies). Preprocessing procedures were performed according to the manufacturer's recommendations and the MicroArray Quality Control project reports [25]. Briefly, a decision matrix determines whether each transcript is reliably detected (i.e., present), marginally detected (i.e., marginal), or not detected (i.e., absent) and calculates signal intensities. Normalization was carried out to the $75^{\text {th }}$ percentile of each array, and each gene to the median, with Gene Spring's normalization option. The hierarchical cluster analysis was performed using the principal component analysis (PCA), the rank correlation of log ratios, and the condition tree clustering option of GeneSpring. The probability was 0.1 and was adjusted by the false-discovery rate for corrections of multiple tests. All raw fluorescence intensity data and microarray image files were deposited within the public repository for microarray-based gene expression data, the "Gene Expression Omnibus" (GEO) (http://www.ncbi.nlm.nih.gov/geo/), complying with the minimum information requirement for microbarray experiments. The GEO accession number for the current experiment is GSE46809.

\section{RESULTS}

\subsection{RNA Yield and Quality}

Table 1 shows the yield and quality parameters of the extracted RNA. The average total yield of RNA per hair root was $317.3 \mathrm{ng} /$ follicle, and the average yields of RNA from a single hair root each from 2 subjects were $286.7 \mathrm{ng} /$ follicle and $409.3 \mathrm{ng} /$ follicle (Table 1(a)). The average total yield of RNA from 5 strands of hair roots was $524.6 \mathrm{ng}$ (128.2 ng/follicle), and the average yields of RNA from 2 subject were $882.7 \mathrm{ng}$ (176.6 $\mathrm{ng} /$ follicle) and $273.9 \mathrm{ng}$ (54.7 ng/follicle) (Table 1(b)). The average yield of 10 strands of hair roots was $418.7 \mathrm{ng}$ (41.9 ng/ follicle), and the average yields of RNA from 2 subjects were $507.4 \mathrm{ng}(50.7 \mathrm{ng} /$ follicle) and $285.6 \mathrm{ng}(28.6 \mathrm{ng} /$ follicle) (Table 1(c)). For the information, the average total yield of RNA from 3 strands of hair roots was 623.5 ng (207.8 ng/follicle), and the average yields of RNA from a single hair root each from 2 subjects were 608.2 $\mathrm{ng}$ (202.7 ng/follicle) and $688.7 \mathrm{ng}$ (229.6 ng/follicle) (data not shown).

The sample quality was determined using the Agilent Bioanalyzer 2100 by calculating the RNA integrity number (RIN). However, RIN is calculated based on the bioanalyzer traces typically produced by hair follicle RNAs; therefore, when a sample had a lower $28 \mathrm{~S}$ rRNA peak but no degradation peaks (Figure 1), the bioanalyzer could not consider the sample as a normal total RNA electropherogram trace. In consequence, RIN for most hair follicle RNA samples were not able to be calculated using default parameters (Table 1). Therefore, in addition to RIN, 28S and 18S clear peaks were also used for determining the RNA quality.

Based on RIN or $28 \mathrm{~S} / 18 \mathrm{~S}$ ratios (2 detected peaks, Figure 1), 14 RNA samples in total were chosen for preamplification for microarray hybridization $(6,7$, and 1 samples from 1, 5, and 10 follicles, respectively) (Tables 1 and 2). Among these 14 samples, 7 did not yield RINs, whereas others had RINs ranging from 6.1 to 7.8 (Table 1). Table 2 shows the enrichment of RNA from these samples following 2 rounds of pre-amplification prior to the microarray analysis. After the first pre-amplification performed on $100 \mathrm{ng}$ of extracted RNA, the average amount of RNA was $2.56 \mu \mathrm{g}(25.6 \mathrm{ng} / \mu \mathrm{l} \times 100 \mu \mathrm{l})$, which was 25.6 fold of the starting material. The average amount of RNA after second amplification was $156.6 \mu \mathrm{g}$ (1556 $\mathrm{ng} / \mu \mathrm{l} \times 100 \mu \mathrm{l})$, which was 78.3 fold of the amount after first amplification. Of these 14 pre-amplified samples, 13 (1 $\mu \mathrm{g}$ each) were selected for DNA microarray analysis (Table 2).

\subsection{Gene Expression Affinity Analysis}

The RNA data from a single hair root were compared to those from 5 or 10 pieces of hair roots. Unlike the

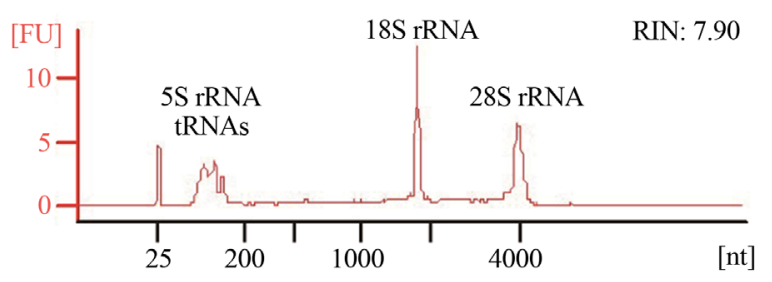

(a)

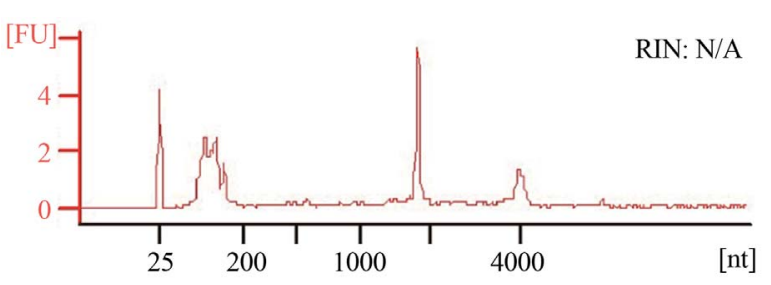

(b)

Figure 1. Representative electropherograms produced by the Agilent Bioanalyzer. (a) An electropherogram with RNA peaks that can be used to calculate RIN; (b) An electropherogram with RNA peaks not suitable for RIN calculation. 
Table 1. Yield and quality of RNA samples. N.D., not detected; o subjected to amplification or microarray analysis.

(a)

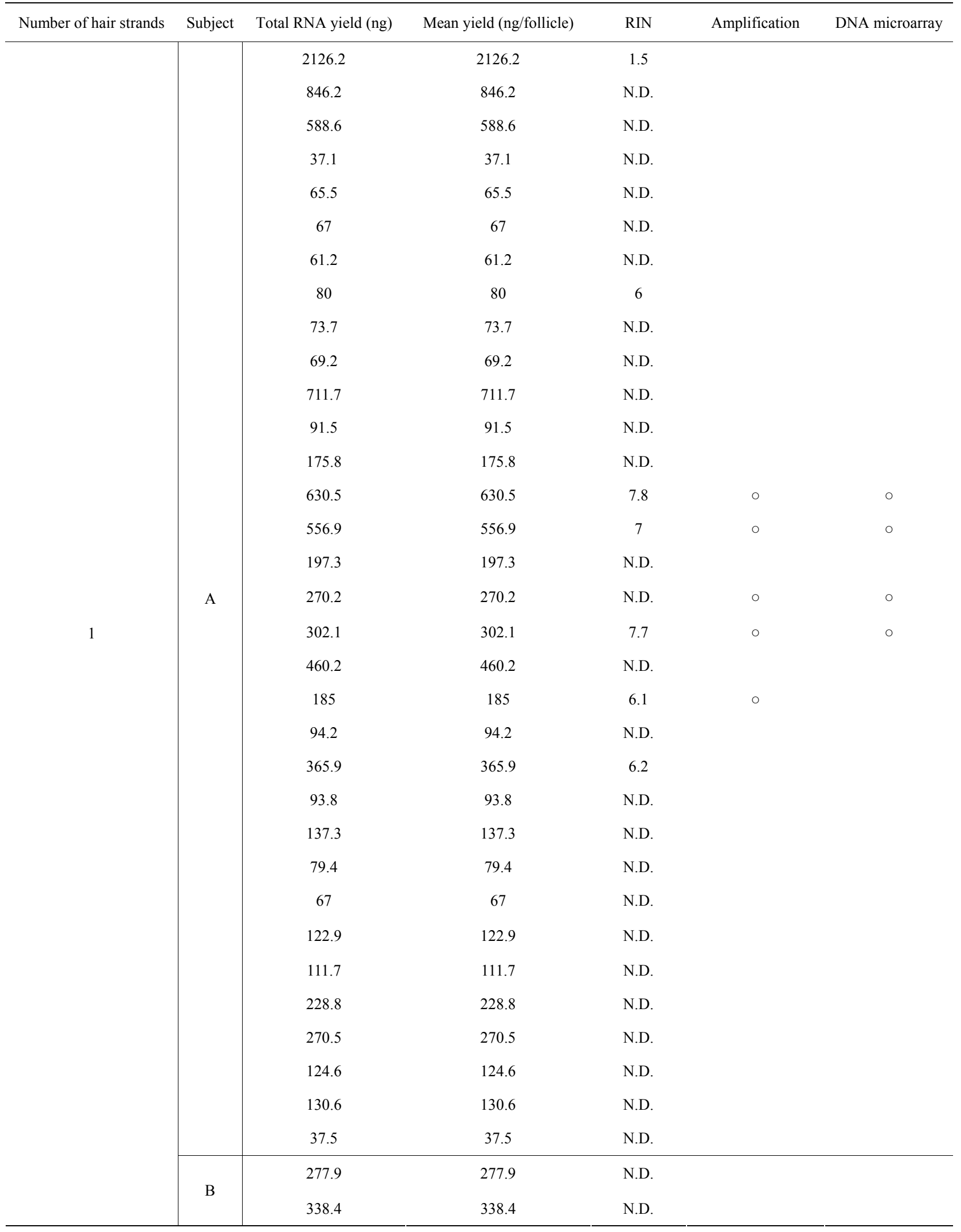




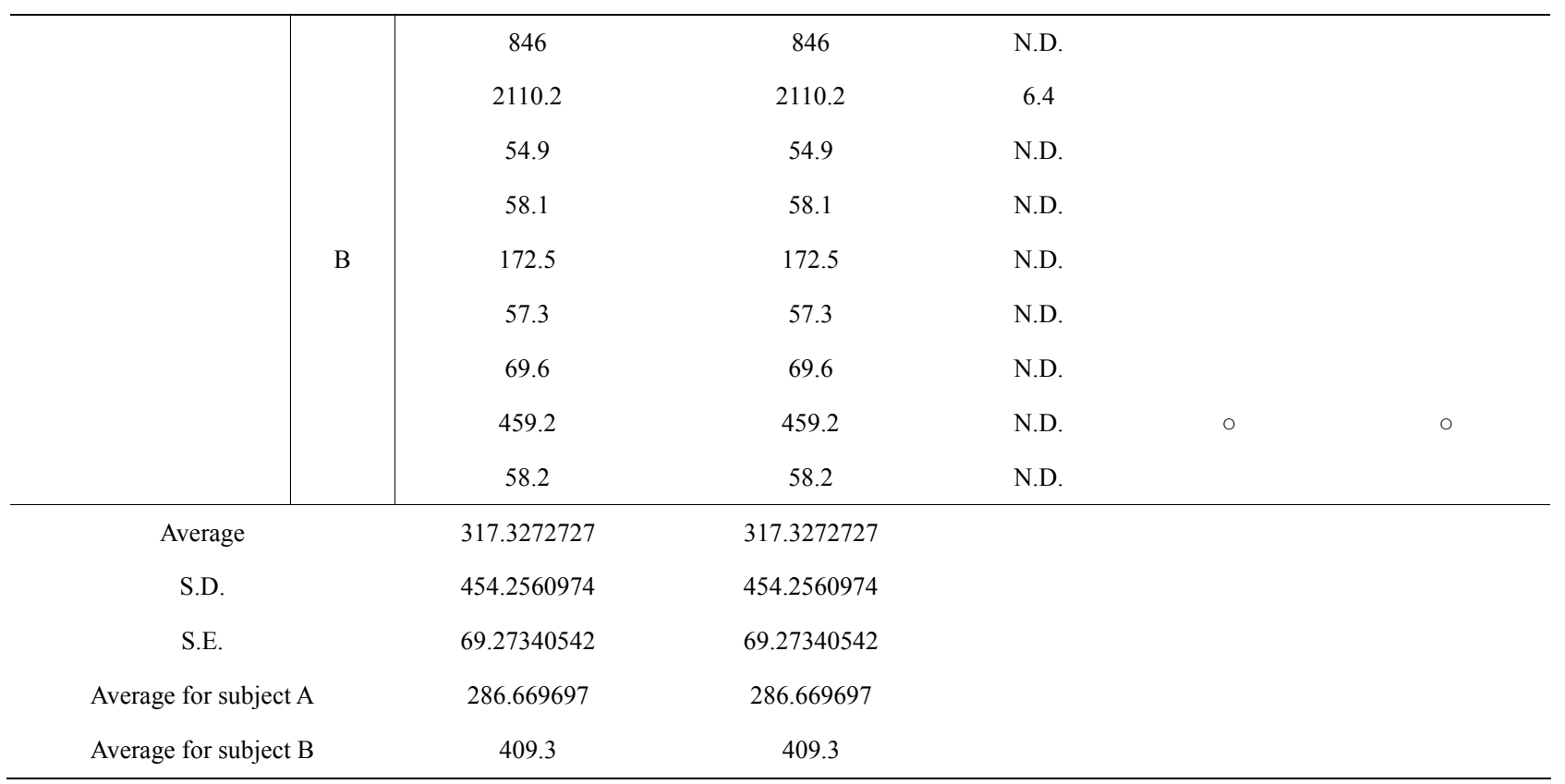

(b)

\begin{tabular}{|c|c|c|c|c|c|c|}
\hline Number of hair strands & Subject & Total RNA yield (ng) & Mean yield (ng/follicle) & RIN & Amplification & DNA microarray \\
\hline \multirow{17}{*}{5} & \multirow{7}{*}{ A } & 898.8 & 179.8 & 6.8 & & \\
\hline & & 727.8 & 145.6 & 6.7 & & \\
\hline & & 1521.5 & 304.3 & 7.1 & $\circ$ & $\circ$ \\
\hline & & 1836.8 & 367.4 & 6.6 & $\circ$ & ○ \\
\hline & & 304.8 & 61 & 7.5 & $\circ$ & ○ \\
\hline & & 353.6 & 70.7 & 3.1 & & \\
\hline & & 535.5 & 107.1 & 7.8 & $\circ$ & ० \\
\hline & \multirow{10}{*}{ B } & 363.8 & 72.8 & N.D. & $\circ$ & $\circ$ \\
\hline & & 513.5 & 102.7 & 6.1 & o & o \\
\hline & & 270.9 & 54.2 & N.D. & $\circ$ & $\circ$ \\
\hline & & 230.3 & 46.1 & N.D. & & \\
\hline & & 131.2 & 26.2 & N.D. & & \\
\hline & & 156.4 & 31.3 & N.D. & & \\
\hline & & 163.5 & 32.7 & N.D. & & \\
\hline & & 459.2 & 91.4 & N.D. & & \\
\hline & & 204.7 & 40.9 & N.D. & & \\
\hline & & 245.7 & 49.1 & N.D. & & \\
\hline \multicolumn{2}{|l|}{ Average } & 524.5882 & 128.1583333 & & & \\
\hline \multicolumn{2}{|l|}{ S.D. } & 484.5583 & 106.9410497 & & & \\
\hline \multicolumn{2}{|l|}{ S.E. } & 121.1396 & 32.24393968 & & & \\
\hline \multicolumn{2}{|c|}{ Average for subject A } & 882.6857 & 176.5571429 & & & \\
\hline \multicolumn{2}{|c|}{ Average for subject B } & 273.92 & 54.74 & & & \\
\hline
\end{tabular}


(c)

\begin{tabular}{|c|c|c|c|c|c|c|}
\hline Number of hair strands & Subject & Total RNA yield (ng) & Mean yield (ng/follicle) & RIN & Amplification & DNA microarray \\
\hline \multirow{5}{*}{10} & \multirow{3}{*}{ A } & 613.1 & 61.3 & 1.6 & & \\
\hline & & 260.4 & 26 & N.D. & & \\
\hline & & 648.7 & 64.9 & N.D. & ○ & ० \\
\hline & \multirow{2}{*}{$\mathrm{B}$} & 180.4 & 18 & N.D. & & \\
\hline & & 390.8 & 39.1 & 1 & & \\
\hline \multicolumn{2}{|l|}{ Average } & 418.68 & 41.86 & & & \\
\hline \multicolumn{2}{|l|}{ S.D. } & 208.15592 & 20.839938 & & & \\
\hline \multicolumn{2}{|l|}{ S.E. } & 104.07796 & 10.419969 & & & \\
\hline \multicolumn{2}{|c|}{ Average for subject A } & 507.4 & 50.733333 & & & \\
\hline \multicolumn{2}{|c|}{ Average for subject $B$} & 285.6 & 28.55 & & & \\
\hline
\end{tabular}

Table 2. RNA yield after amplification.

\begin{tabular}{|c|c|c|c|c|c|c|}
\hline \multirow{2}{*}{$\begin{array}{l}\text { Number of } \\
\text { hair strands }\end{array}$} & \multirow{2}{*}{ Subject } & \multirow{2}{*}{$\begin{array}{l}\text { Extracted concentration } \\
\quad(\mathrm{ng} / \mu \mathrm{l})(\times 10)\end{array}$} & \multirow{2}{*}{$\begin{array}{l}\text { Mean yield } \\
\text { (ng/follicle) }\end{array}$} & \multicolumn{2}{|c|}{ Amplification $(\mathrm{ng} / \mu \mathrm{l})$} & \multirow{2}{*}{ DNA microarray } \\
\hline & & & & $1 \mathrm{st}(\times 100)$ & 2 nd $(\times 100)$ & \\
\hline \multirow{5}{*}{1} & \multirow{5}{*}{ A } & 63.05 & 630.5 & 67.93 & 1933.1 & ० \\
\hline & & 55.69 & 556.9 & 113.98 & 1895.43 & o \\
\hline & & 27.02 & 270.2 & 10.15 & 1879.84 & ० \\
\hline & & 30.21 & 302.1 & 5.55 & 1562.34 & ० \\
\hline & & 18.5 & 185 & 4.87 & 1043.56 & \\
\hline \multirow{4}{*}{5} & \multirow{4}{*}{ A } & 3.048 & 6.096 & 25.03 & 1787.98 & ० \\
\hline & & 5.355 & 10.71 & 15.97 & 1354.34 & o \\
\hline & & 15.215 & 30.43 & 19.71 & 1350.56 & ० \\
\hline & & 18.368 & 18.368 & 16.26 & 1597.09 & ० \\
\hline 10 & A & 64.87 & 648.7 & 15.83 & 1676.85 & ० \\
\hline 1 & $\mathrm{~B}$ & 4.592 & 45.92 & 12.66 & 1118.27 & ० \\
\hline \multirow{3}{*}{5} & \multirow{3}{*}{$\mathrm{B}$} & 3.638 & 7.276 & 17.64 & 1805.3 & ० \\
\hline & & 5.135 & 10.27 & 12.42 & 1589.98 & ० \\
\hline & & 2.709 & 5.418 & 20.27 & 1330.05 & $\circ$ \\
\hline & & & Average & 25.5907143 & 1566.0493 & \\
\hline & & & S.D. & 29.6345159 & 288.55833 & \\
\hline & & & S.E. & 8.21913588 & 80.031682 & \\
\hline
\end{tabular}

amount of RNA initially extracted from these hair roots, the amount of amplified RNA was sufficient for microarray analyses. To analyze the sample-specific patterns in gene expression profiles, the PCA analysis, the rank correlation of log ratios, and hierarchical clusters analysis were applied. PCA was used to demonstrate the homogeneity level of the transcriptional profiles of ana- lyzed samples. In a PCA plot, samples with similar expression profiles are positioned in the proximity to each other [26,27]. The position of each sample was plotted against the X-, Y-, and Z-axes in a three-dimensional (3D) space (Figure 2), in which the closer distance of the samples to each other in $3 \mathrm{D}$; therefore, the homology between samples is high. As shown in Figure 2, the ex- 


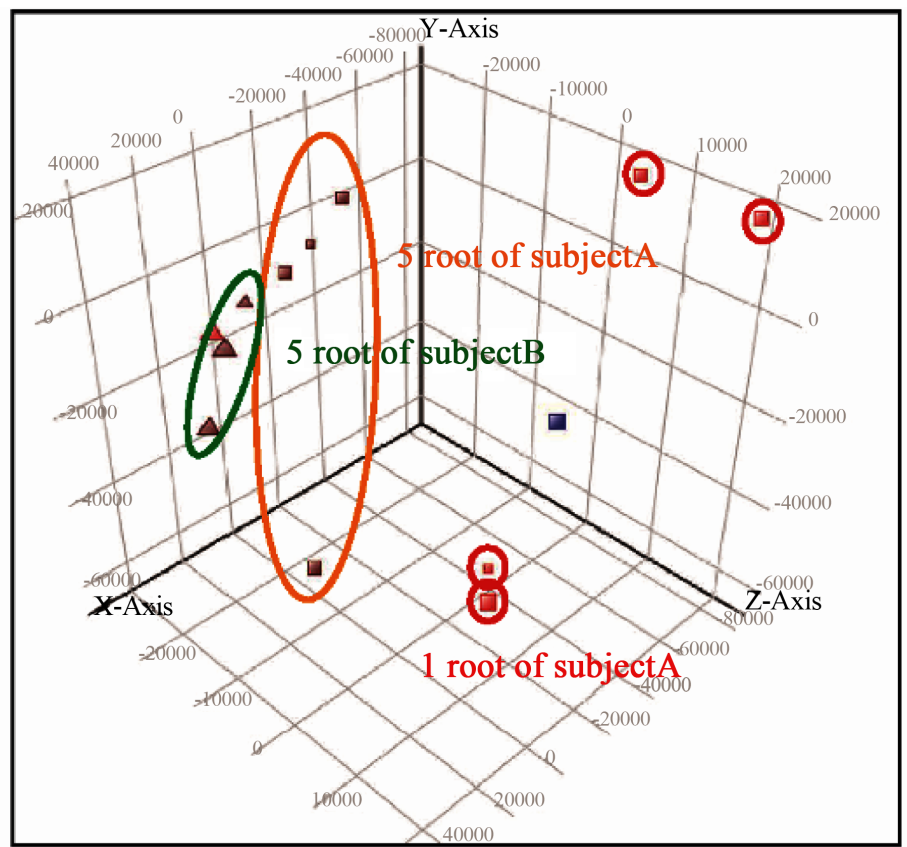

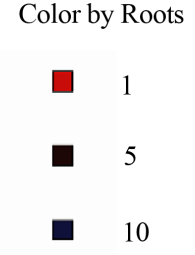

Shape by Subjects

A

$\Delta \quad \mathrm{B}$
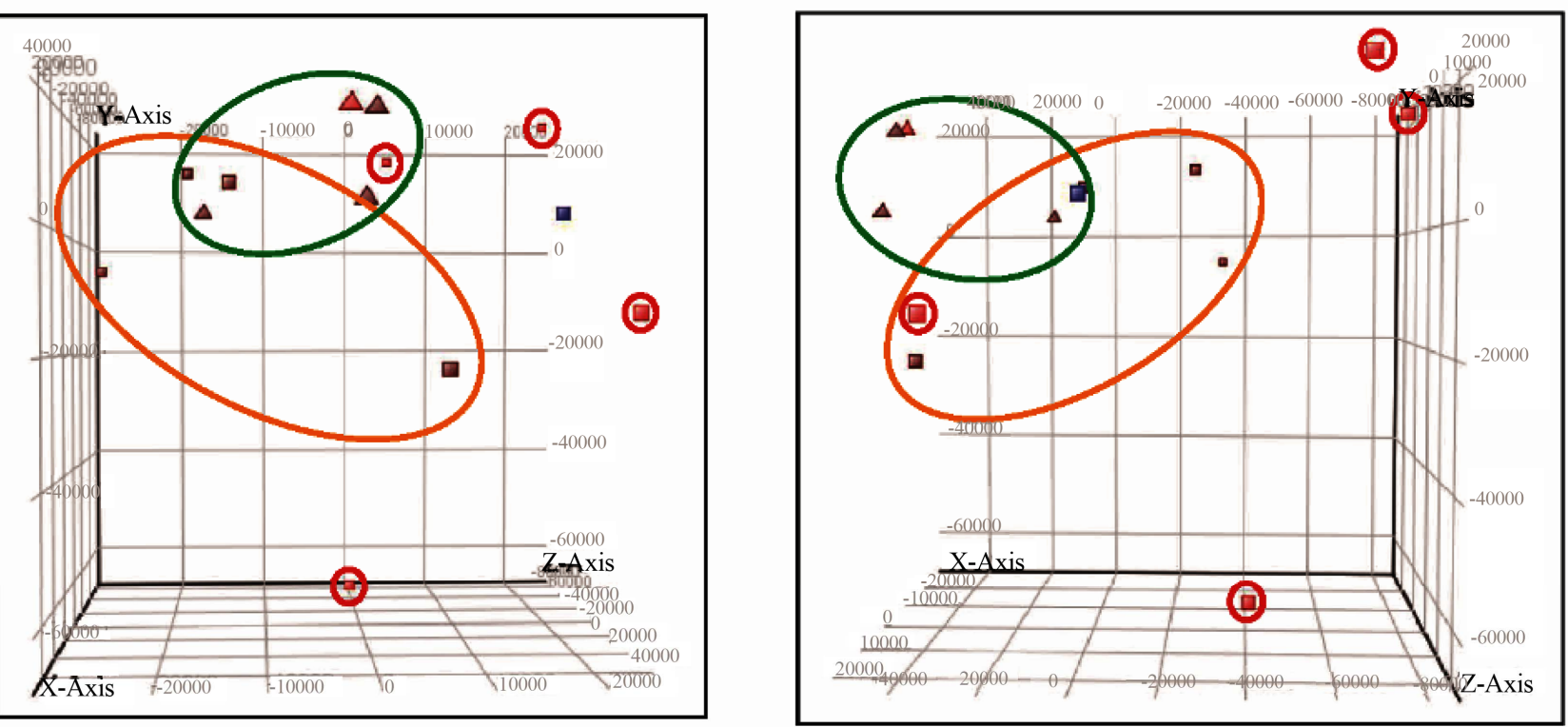

Figure 2. Three-dimensional images of principal component analysis (PCA). The closer the distance between samples, the higher the homology is between them.

pression data from RNA samples extracted from 5 follicles, but not a single follicle, were found to have higher levels of homogeneity. On the other hand, large variability was observed among the samples derived from 1 follicle.

The variability among samples was also evaluated using the rank correlation of $\log$ ratios. As shown in Figure 3, spots colored in red represent discrepancy in the samples; in other words, the variability among samples was relatively low. These results also suggest that the smaller the number of follicles from which RNA is extracted, the larger the variability is among samples. Notably, samplespecific differences were still present even when RNA was extracted from the same number of follicles (Figure 3).

To evaluate the homogeneity among multiple genes in all samples, the hierarchical analysis was performed using condition tree clustering (Figure 4). The results indicate clear resolution between the subjects, as well as large differences between samples originating from a single follicle. As for the samples derived from 5 follicles, the level of variability was low, and therefore, the gene 


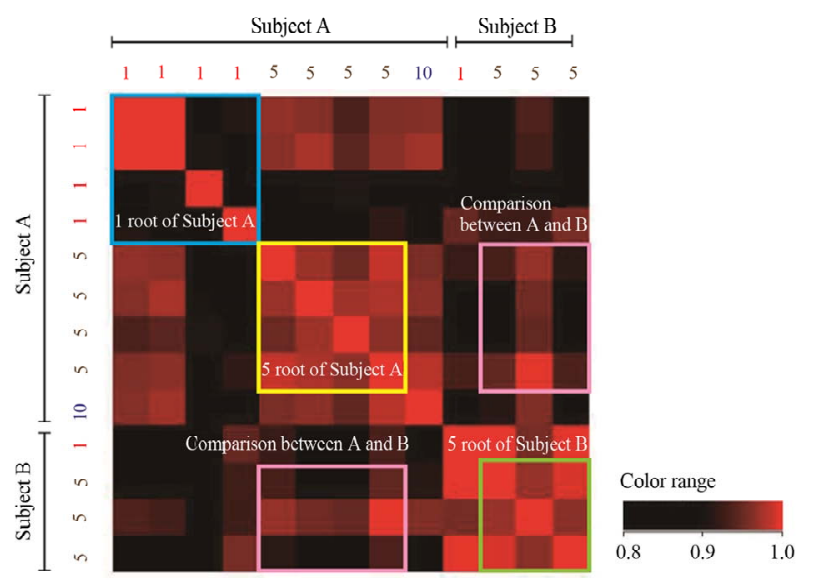

Figure 3. Correlation plot as a comparison of rank concordance. The more red between each sample, homology between samples is high. Darker shades depict lower rank correlations.

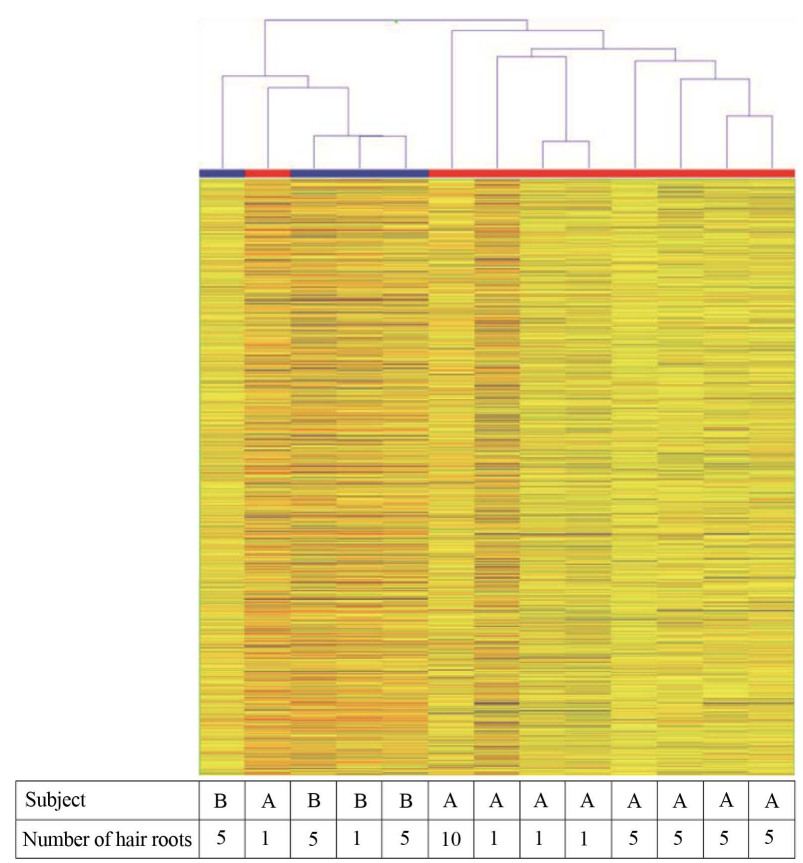

Figure 4. Hierarchical cluster analysis by condition tree clustering. The characteristics of individual subjects were separated.

expression data were considered to be reproducible and significant (Figure 4). On the other hand, the samples derived from 1 follicle showed large variability, so the sample of subject A was separated as the group of subject B.

\subsection{Certification of Hair Gene Expressions}

To confirm the integrity of RNA extracted from the hair, the expression levels of hair-specific genes in these samples were analyzed. Hair root-specific genes were chosen by referencing reports by Ohyama et al. [2006] and Kloepper et al. [2008]. In the sub-bulge region of hair roots,
22 out of 24 reported genes were expressed in the samples (Table 3(a)). As for the hair bulge region, the expression of 16 out of 17 genes was confirmed (Table 3(b)). In addition, the expression of 18 out of 22 genes related to immunophenotyping of the human bulge region was also detected (Table 3(c)).

\section{DISCUSSION}

Several groups have extracted RNA from rodent and human hair follicles [24,28-34]. In most cases, the hair samples were stored in dissolution buffers, such as RNA later [24] or RN easy [28], prior to the analysis. However, for the HAIR experiment, the hair samples from astronauts must be stored without buffers at $-80^{\circ} \mathrm{C}$, due to the limited resource in space. Therefore, the same storage method was employed in this study. The quality of RNA extracted from the samples stored at $-80^{\circ} \mathrm{C}$ was first investigated, followed by examination of whether the extracted RNA was of sufficient quality and quantity for subsequent DNA microarray analysis.

In this study, different RNA samples extracted from 1, 5 , and 10 strands of hair follicles using ISOGEN Reagent were compared. Extracted RNA was then amplified prior to the DNA microarray analysis. As shown in Table 1, some amount of RNA could be extracted even from 1 hair follicle. Notably, the yields were somewhat variable, and the amount of extracted RNA was not dependent on the number of hair follicles. While the reason for these results is unclear, it is likely that the device (NanoDrop ND-1000 spectrophotometer) was unable to correctly detect the amounts of RNA that were near to or less than its limit of detection. On the other hand, the electropherograms of these samples indicated intactness and good quality (Figure 1). Studies have shown that less than 5 ng of total RNA could be amplified and used for microarray hybridization $[24,35,36]$. With the incorporation of a pre-amplification process, the RNA samples were amplified effectively to provide sufficient materials for microarray hybridization (Table 2).

In the current study, the RNA yields from the hair samples were $>18 \mathrm{ng}$ per hair follicle, which is similar to the results reported by some researchers [24,37]. Although the amount of extracted RNA was insufficient for direct microarray analysis, the RNA amplification procedure allowed us to perform the microarray profiling, even on the samples that had only small amounts of RNA (Tables 1 and 2) [24,38-41]. In addition, the quality of RNA is important for judging whether the samples could be applied to the microarray analysis. In this study, the quality of RNA was evaluated on the basis of RIN (Table 1). RNA, although thermodynamically stable, is rapidly degraded by ubiquitous RNase enzymes [23]; as a result, short fragments of degraded RNA appear in the samples $[42,43]$. Using agarose gel electrophoresis, 2 RNA bands 
Table 3. List of hair root-related genes. Genes shown in dark columns were not detected in the samples. a) Sub-bulge; b) Bulge; c) Immunophenotype of the human bulge region.

(a)

\begin{tabular}{|c|c|}
\hline Gene symbol & Description \\
\hline SDC2 & Homo sapiens syndecan 2 (SDC2), mRNA [NM_002998] \\
\hline ANGPTL7 & H. sapiens angiopoietin-like 7 (ANGPTL7), mRNA [NM_021146] \\
\hline SLC1A4 & $\begin{array}{l}\text { H. sapiens solute carrier family } 1 \text { (glutamate/neutral amino acid transporter), member } 4 \text { (SLC1A4), } \\
\text { transcript variant } 1 \text {, mRNA [NM_003038] }\end{array}$ \\
\hline TYMS & H. sapiens thymidylate synthetase (TYMS), mRNA [NM_001071] \\
\hline CDK1 & H. sapiens cyclin-dependent kinase 1 (CDK1), transcript variant 1, mRNA [NM_001786] \\
\hline TOP2A & H. sapiens topoisomerase (DNA) II alpha 170kDa (TOP2A), mRNA [NM_001067] \\
\hline VAV3 & H. sapiens vav 3 guanine nucleotide exchange factor (VAV3), transcript variant 1, mRNA [NM_006113] \\
\hline GPC4 & H. sapiens glypican 4 (GPC4), mRNA [NM_001448] \\
\hline MCAM & H. sapiens melanoma cell adhesion molecule (MCAM), mRNA [NM_006500] \\
\hline SLC4A7 & H. sapiens solute carrier family 4, sodium bicarbonate cotransporter, member 7 (SLC4A7), mRNA [NM_003615] \\
\hline FEN1 & H. sapiens flap structure-specific endonuclease 1 (FEN1), mRNA [NM_004111] \\
\hline TIMP3 & H. sapiens TIMP metallopeptidase inhibitor 3 (TIMP3), mRNA [NM_000362] \\
\hline LAMB1 & Laminin, beta 1 [Source: HGNC symbol; Acc:6486] [ENST00000393559] \\
\hline FGF18 & H. sapiens fibroblast growth factor 18 (FGF18), mRNA [NM_003862] \\
\hline СОМP & H. sapiens cartilage oligomeric matrix protein (COMP), mRNA [NM_000095] \\
\hline PDGFC & H. sapiens platelet derived growth factor C (PDGFC), transcript variant 1, mRNA [NM_016205] \\
\hline LAMB1 & H. sapiens laminin, beta 1, mRNA (cDNA clone IMAGE: 4889995) containing frame-shift errors [BC044633] \\
\hline KPNA2 & H. sapiens karyopherin alpha 2 (RAG cohort 1, importin alpha 1) (KPNA2), mRNA [NM_002266] \\
\hline PRC1 & H. sapiens protein regulator of cytokinesis 1 (PRC1), transcript variant 1, mRNA [NM_003981] \\
\hline LAMB1 & H. sapiens laminin, beta 1 (LAMB1), mRNA [NM_002291] \\
\hline COL11A1 & H. sapiens collagen, type XI, alpha 1 (COL11A1), transcript variant B, mRNA [NM_080629] \\
\hline SLC7A1 & H. sapiens solute carrier family 7 (cationic amino acid transporter, $\mathrm{y}+$ system), member 1 (SLC7A1), mRNA [NM_003045] \\
\hline PCDH8 & H. sapiens protocadherin 8 (PCDH8), transcript variant 1, mRNA [NM_002590] \\
\hline RRM2 & H. sapiens ribonucleotide reductase M2 (RRM2), transcript variant 2, mRNA [NM_001034] \\
\hline
\end{tabular}

(b)

\begin{tabular}{cc}
\hline Gene symbol & Description \\
\hline DIO2 & H. sapiens deiodinase, iodothyronine, type II (DIO2), transcript variant 1, mRNA [NM_013989] \\
DPYSL2 & H. sapiens dihydropyrimidinase-like 2 (DPYSL2), transcript variant 2, mRNA [NM_001386] \\
FST & H. sapiens follistatin (FST), transcript variant FST344, mRNA [NM_013409] \\
FZD1 & $\begin{array}{r}\text { H. sapiens frizzled family receptor 1 (FZD1), mRNA [NM_003505] } \\
\text { DCT }\end{array}$ \\
HPYSL3 & $\begin{array}{r}\text { H. sapiens dihydropyrimidinase-like 3 (DPYSL3), transcript variant 2, mRNA [NM_001387] } \\
\text { transcript variant 1, mRNA [NM_001922] }\end{array}$ \\
DCN & $\begin{array}{r}\text { H. sapiens decorin (DCN), transcript variant A1, mRNA [NM_001920] } \\
\text { HERINF1 }\end{array}$ \\
\hline
\end{tabular}


Continued

\begin{tabular}{cc}
\hline WIF1 & H. sapiens WNT inhibitory factor 1 (WIF1), mRNA [NM_007191] \\
KRT15 & H. sapiens keratin 15 (KRT15), mRNA [NM_002275] \\
PHLDA1 & H. sapiens pleckstrin homology-like domain, family A, member 1 (PHLDA1), mRNA [NM_007350] \\
DKK3 & H. sapiens dickkopf homolog 3 (Xenopus laevis) (DKK3), transcript variant 1, mRNA [NM_015881] \\
PHLDA1 & Pleckstrin homology-like domain, family A, member 1 [Source: HGNC symbol; Acc:8933] [ENST00000266671] \\
TGFB2 & H. sapiens transforming growth factor, beta 2 (TGFB2), transcript variant 2, mRNA [NM_003238] \\
DKK3 & H. sapiens dickkopf homolog 3 (X. laevis) (DKK3), transcript variant 1, mRNA [NM_015881] \\
ANGPTL2 & H. sapiens angiopoietin-like 2 (ANGPTL2), mRNA [NM_012098] \\
DIO2 & H. sapiens deiodinase, iodothyronine, type II (DIO2), transcript variant 4, mRNA [NM_001242502] \\
\hline
\end{tabular}

(c)

\begin{tabular}{|c|c|}
\hline Gene symbol & Description \\
\hline TNC & H. sapiens tenascin C (TNC), mRNA [NM_002160] \\
\hline GJA1 & H. sapiens gap junction protein, alpha 1, 43kDa (GJA1), mRNA [NM_000165] \\
\hline FBN1 & H. sapiens fibrillin 1 (FBN1), mRNA [NM_000138] \\
\hline NES & H. sapiens nestin (NES), mRNA [NM_006617] \\
\hline CD200 & H. sapiens CD200 molecule (CD200), transcript variant 2, mRNA [NM_001004196] \\
\hline ITGB1 & $\begin{array}{l}\text { H. sapiens integrin, beta } 1 \text { (fibronectin receptor, beta polypeptide, antigen CD29 includes MDF2, MSK12) (ITGB1), } \\
\text { transcript variant 1E, mRNA [NM_133376] }\end{array}$ \\
\hline NID2 & Nidogen 2 (osteonidogen) [Source: HGNC symbol; Acc:13389] [ENST00000395707] \\
\hline FN1 & H. sapiens fibronectin 1 (FN1), transcript variant 7, mRNA [NM_054034] \\
\hline ITGA6 & H. sapiens integrin, alpha 6 (ITGA6), transcript variant 2, mRNA [NM_000210] \\
\hline CD34 & H. sapiens CD34 molecule (CD34), transcript variant 1, mRNA [NM_001025109] \\
\hline LHX2 & H. sapiens LIM homeobox 2 (LHX2), mRNA [NM_004789] \\
\hline NID1 & H. sapiens nidogen 1 (NID1), mRNA [NM_002508] \\
\hline FBN2 & H. sapiens fibrillin 2 (FBN2), mRNA [NM_001999] \\
\hline LTBP1 & H. sapiens latent transforming growth factor beta binding protein 1 (LTBP1), transcript variant 1, mRNA [NM_206943] \\
\hline NES & H. sapiens nestin (NES), mRNA [NM_006617] \\
\hline ITGA6 & H. sapiens integrin, alpha 6 (ITGA6), transcript variant 2, mRNA [NM_000210] \\
\hline LTBP1 & H. sapiens latent transforming growth factor beta binding protein 1 (LTBP1), transcript variant 1, mRNA [NM_206943] \\
\hline FBN3 & H. sapiens fibrillin 3 (FBN3), mRNA [NM_032447] \\
\hline KRT15 & H. sapiens keratin 15 (KRT15), mRNA [NM_002275] \\
\hline CD200 & H. sapiens CD200 molecule (CD200), transcript variant 2, mRNA [NM_001004196] \\
\hline NID2 & H. sapiens nidogen 2 (osteonidogen) (NID2), mRNA [NM_007361] \\
\hline CD34 & H. sapiens CD34 molecule (CD34), transcript variant 2, mRNA [NM_001773] \\
\hline
\end{tabular}

comprising $28 \mathrm{~S}$ and $18 \mathrm{~S}$ ribosomal RNA can be readily visualized in gel images. RNA is considered of high quality when the ratio of 28S: $18 \mathrm{~S}$ bands are more than 2 . The RIN numbers are calculated by allowing the classification of total RNA, based on a numbering system from 1 (the most degraded) to 10 (the most intact) [22, 23]. Generally, RNA sample with a RIN number of more than 7 are considered suitable for genetic analyses [43]. Interestingly, some researchers reported that with care, meaningful microarray data could be obtained from RNA 
samples of impaired quality [44], whereas others suggested that degradation does not preclude the microarray analysis if comparison is done between samples with comparable RNA integrity [42]. In this study, Agilent Bioanalyzer 2100 was used to determine the sample quality by calculating RIN, based on the Bioanalyzer traces typically yielded by hair follicle RNAs. Therefore, when a sample had a lower 28S rRNA peak but no degradation peaks (Figure 1), the system could not consider the sample as a normal total RNA electropherogram trace. Another issue was the existence of a 5S rRNA or tRNA peak in the Bioanalyzer electropherogram (Figure 1), which may affect the calculation of RIN when these peaks are larger than that of $18 \mathrm{~S}$ or $28 \mathrm{~S}$ ribosomal RNA [23]. In this study, RNA was extracted using ISOGEN Reagent, which could not remove $5 \mathrm{~S}$ rRNA or tRNA due to the lack of column elution steps. As a result, RIN was unable to be calculated for most hair follicle RNA samples using default parameters (Table 1).

Based on RIN or $28 \mathrm{~S} / 18 \mathrm{~S}$ ratios, a total of 14 RNA samples $(6,7$, and 1 samples from 1, 5, and 10 follicles, respectively) were chosen for pre-amplification of microarray hybridization (Tables $\mathbf{1}$ and 2). Notably, 19,361 genes were expressed in more than 1 sample from among all samples. In total, 10,593 genes were expressed in all samples. By referencing publically available data set from previous microarray analyses $[27,45,46]$, the differences depending on the number of hair follicles were compared by the clustering analysis of the microarray data. Using the PCA analysis, similarities and differences that were dependent on the number of hair follicles were also observed (Figure 2). In the PCA plot, 4 spots from 1 follicle of 1 subject were scattered, whereas some spots from 5 follicles of 2 subjects were located closely for respective individuals. These phenomena suggest that the homogeneity of gene expression is largely dependent on the number of cells from which RNA is extracted. That is, as the number of hair follicles is increased, the homology and uniformity are increased. The variability among samples was also evaluated using the rank correlation of log ratios. As shown in Figure 3, the color between the samples from 5 hair follicles became redder than that between the samples from 1 hair follicle. In agreement with the PCA results, the rank correlation of log ratios analysis suggests that the homogeneity is increased, as the number of hair follicles is increased. These results seem to be reasonable, because the hereditary properties of individual hair follicles would disappear when being averaged by the increasing number of hair cells. This finding is advantageous for the HAIR experiment on astronauts, since the goal of the experiment is to detect gene expression changes in the body during spaceflight, but not the single hair-specific patterns. The hierarchical cluster analysis was also performed by applying condition tree clustering (Figure 4), through which the mRNA expression profiles of the 2 subjects could be distinguished. This result will be informative for successful implementation of the HAIR experiment, because the focus of the study is on the individual data, rather than the average data, from the subjects. Human hair analysis will be further developed along the same lines as a method to evaluate the health conditions of astronauts because it allows the examination of astronaut-specific patterns in space. Using the hierarchical cluster analysis, Kim et al. [2006] previously reported no difference in the gene expression in hair roots between males and females. Interestingly, 2 subjects in this study were males, and their individual characteristics could be separated (Figure 4). While Kim et al. obtained their samples at the same time from many subjects, the samples in this study were collected at various times from 2 subjects. This margin may reflect the differences between their results and ours.

Next, to confirm the integrity of mRNA in the samples, the expression of hair follicle-specific genes was analyzed (Table 3). For hair sub-bulge-related genes, the expression of 22 out of 24 reported genes was detected (Table 3(a)). Out of 17 genes of hair bulge, the expression of 16 genes was confirmed (Table 3(b)). In addition, 18 out of 22 genes related to human epithelial hair follicle stem cells and bulge niche markers were found to be expressed (Table 3(c)). Together, these results suggest that hair root-related genes were expressed in the samples tested in this study. Therefore, it is desirable that the genes of other organs except hair roots are included in our samples, and there is not any problem. In this time, because we can confirm at least the existence of genes related with hair roots in our samples, there are no methodologically problems. Nevertheless, the newly developed methods are appropriate for analyzing biological samples derived from astronauts in the HAIR experiment.

It is worth noting that the gene expression in the skin has been shown to be different between subjects who had hyperkeratotic skin lesions and those who did not [47]. In addition, Yin et al. also suggested that DNA damage was induced in the mouse skin upon exposure to ultraviolet radiation [48]. These results suggested that the skin, which contains hair follicles, receive the effects on gene condition by physiological changes or extraordinary environments. Although these studies were not performed on human hair follicles, it is indeed possible to investigate the effects of various space environments (i.e., microgravity, space radiation, physiological changes, or mental conditions) on astronauts by analyzing the gene expression in their hair follicles.

\section{CONCLUSION}

Taken together, these results suggest the following points. First, it is possible to perform a robust gene expression 
analysis on hair samples stored at $-80^{\circ} \mathrm{C}$, even without a fixation buffer. Second, the newly modified method of mRNA extraction and analysis is effective in detecting differential genes expression in samples containing only 5 hairs.

The hair samples provided useful physiological information for examining the effect of spaceflight. A novel method was developed to extract and amplify RNA from 5 hair roots, which is the same number of hair roots used in the space experiment; therefore, the method can be applied for genetic analysis of astronauts' hair samples. Currently, sufficient samples are being gathered from astronauts. The analysis of hair roots from the ISS crews will support the development of a simple and effective diagnostic measure for metabolic changes and help evaluate astronauts' health conditions in response to longterm spaceflight.

\section{ACKNOWLEDGEMENTS}

This study was supported in part by the JAXA-ISS Space Medicine Program Grant from the Japan Aerospace Exploration Agency and a Grant-in-Aid for Young Scientists (B-21800096, M.T.) from the Japan Society for the Promotion of Science.

We thank Tohko Hashizume for the useful comments on and support for our study. We would also like to express our appreciation to Dr. Hiroshi Ohshima and Dr. Toshiko Ohta for their constructive advice and supervision of this manuscript.

\section{REFERENCES}

[1] Terada, M., Kawano, F., Ishioka, N., Higashibata, A., Majima, H.J., Yamazaki, T., et al. (2012) Biomedical analysis of rat body hair after hindlimb suspension for 14 days. Acta Astronaut, 73, 23-29. http://dx.doi.org/10.1016/j.actaastro.2011.12.016

[2] Sperling, L.C. (1991) Hair anatomy for the clinician. Journal of the American Academy of Dermatology, 25, 117.

[3] Stenn, K.S. and Paus, R. (2001) Controls of hair follicle cycling. Physiological Reviews, 81, 449-494.

[4] Chuong, C.M. (1998) Molecular basis of epithelial appendage morphogenesis. Austin, 444.

[5] Hardy, M.H. (1992) The secret life of the hair follicle. Trends in Genetics, 8, 55-61.

[6] Paus, R. and Cotsarelis, G. (1999) The biology of hair follicles. The New England Journal of Medicine, 341, 491-497.

[7] Chase, E.S., Weinsier, R.L., Laven, G.T. and Krumdieck, C.L. (1981) Trichotillometry: the quantitation of hair pluckability as a method of nutritional assessment. The American Journal of Clinical Nutrition, 34, 2280-2286.

[8] Jelliffe, D.B. (1966) The assessment of the nutritional status of the community (with special reference to field surveys in developing regions of the world). Monograph Series. World Health Organization, 53, 3-271.
[9] Yasuda, H., Yonasiro, T., Yoshida, K., Shibazaki, T., Ishii, T. and Tsutsui, T. (2005) High toxic metal levels in scalp hair of infants and children. Biomedical Research on Trace Elements, 16, 39-45.

[10] Suzuki, T., Hongo, T., Yoshinaga, J., Imai, H., Nakazawa, M., Matsuo, N., et al. (1993) The hair-organ relationship in mercury concentration in contemporary Japanese. Archives of Environmental Health, 48, 221-229.

[11] Wibowo, A.A., Herber, R.F., Das, H.A., Roeleveld, N. and Zielhuis, R.L. (1986) Levels of metals in hair of young children as an indicator of environmental pollution. Environmental Research, 40, 346-356.

[12] Harada, M., Nakachi, S., Cheu, T., Hamada, H., Ono, Y., Tsuda, T., et al. (1987) Monitoring of mercury pollution in Tanzania: Relation between head hair mercury and health. Science of the Total Environment, 227, 249-256.

[13] Yasutake, A., Matsumoto, M., Yamaguchi, M. and Hachiya, N. (2003) Current hair mercury levels in Japanese: Survey in five districts. Tohoku Journal of Experimental Medicine, 199, 161-169.

[14] Rodushkin, I. and Axelsson, M.D. (2000) Application of double focusing sector field ICP-MS for multielemental characterization of human hair and nails. Part I. Analytical methodology. Science of the Total Environment, 250, 83-100.

[15] Batzevich, V.A. (1995) Hair trace element analysis in human ecology studies. Science of the Total Environment, 164, 89-98.

[16] Bascove, M., Huin-Schohn, C., Guéguinou, N., Tschirhart, E. and Frippiat, J.P. (2009) Spaceflight-associated changes in immunoglobulin VH gene expression in the amphibian Pleurodeles waltl. FASEB Journal, 23, 1607-1615.

[17] Allen, D.L., Bandstra, E.R., Harrison, B.C., Thorng, S., Stodieck, L.S., Kostenuik, P.J., et al. (2009) Effects of spaceflight on murine skeletal muscle gene expression. Journal of Applied Physics, 106, 582-595.

[18] Nikawa, T., Ishidoh, K., Hirasaka, K., Ishihara, I., Ikemoto, M., Kano, M., et al. (2004) Skeletal muscle gene expression in space-flown rats. FASEB Journal, 18, 522524.

[19] Sandonà, D., Desaphy, J.F., Camerino, G.M., Bianchini, E., Ciciliot, S., Danieli-Betto, D., et al. (2012) Adaptation of mouse skeletal muscle to long-term microgravity in the MDS mission. PLoS One, 7, e33232.

[20] Schatten, H., Lewis, M.L. and Chakrabarti, A. (2001) Spaceflight and clinorotation cause cytoskeleton and mitochondria changes and increases in apoptosis in cultured cells. Acta Astronaut, 49, 399-418.

[21] Sato, T., Sato, G., Shoji, Y., Itou, T. and Sakai, T. (2006) Extraction and detection of mRNA from horsehair. The Journal of Veterinary Medical Science, 68, 503-506.

[22] Dev, H., Rickman, D., Sooriakumaran, P., Srivastava, A., Grover, S., Leung, R., et al. (2011) Biobanking after robotic-assisted radical prostatectomy: a quality assessment of providing prostate tissue for RNA studies. Journal of Translational Medicine, 9, 121.

[23] Schroeder, A., Mueller, O., Stocker, S., Salowsky, R., Leiber, M., Gassmann, M., et al. (2006) The RIN: An RNA 
integrity number for assigning integrity values to RNA measurements. BMC Molecular Biology, 7, 3.

[24] Kim, S.J., Dix, D.J., Thompson, K.E., Murrell, R.N., Schmid, J.E., Gallagher, J.E., et al. (2006) Gene expression in head hair follicles plucked from men and women. Annals of Clinical \& Laboratory Science, 36, 115-126.

[25] Guo, L., Lobenhofer, E.K., Wang, C., Shippy, R., Harris, S.C., Zhang, L., et al. (2006) Rat toxicogenomic study reveals analytical consistency across microarray platforms. Nature Biotechnology, 24, 1162-1169. http://dx.doi.org/10.1038/nbt1238

[26] Perrini, S., Ficarella, R., Picardi, E., Cignarelli, A., Barbaro, M., Nigro, P., et al. (2013) Differences in gene expression and cytokine release profiles highlight the heterogeneity of distinct subsets of adipose tissue-derived stem cells in the subcutaneous and visceral adipose tissue in humans. PLoS One, $\mathbf{8}$, e57892. http://dx.doi.org/10.1371/journal.pone.0057892

[27] Petersen, D., Chandramouli, G.V., Geoghegan, J., Hilburn, J., Paarlberg, J., Kim, C.H., et al. (2005) Three microarray platforms: An analysis of their concordance in profiling gene expression. BMC Genomics, 6, 63. http://dx.doi.org/10.1186/1471-2164-6-63

[28] Akashi, M., Soma, H., Yamamoto, T., Tsugitomi, A., Yamashita, S., Nishida, E., et al. (2010) Noninvasive method for assessing the human circadian clock using hair follicle cells. Proceedings of the National Academy of Sciences of the USA, 107, 15643-15648.

[29] Schlake, T. and Boehm, T. (2001) Expression domains in the skin of genes affected by the nude mutation and identified by gene expression profiling. Mechanisms of Development, 109, 419-422. http://dx.doi.org/10.1016/S0925-4773(01)00538-X

[30] Schlake, T., Beibel, M., Weger, N. and Boehm, T. (2004) Major shifts in genomic activity accompany progression through different stages of the hair cycle. Gene Expression Patterns, 4, 141-152. http://dx.doi.org/10.1016/j.modgep.2003.09.009

[31] Lin, K.K., Chudova, D., Hatfield, G.W., Smyth, P. and Andersen, B. (2004) Identification of hair cycle-associated genes from time-course gene expression profile data by using replicate variance. Proceedings of the National Academy of Sciences of the USA, 101, 15955-15960. http://dx.doi.org/10.1073/pnas.0407114101

[32] Xu, X., Lyle, S., Liu, Y., Solky, B. and Cotsarelis, G. (2003) Differential expression of cyclin D1 in the human hair follicle. American Journal of Pathology, 163, 969978. http://dx.doi.org/10.1016/S0002-9440(10)63456-6

[33] Little, J.C., Westgate, G.E., Evans, A. and Granger, S.P. (1994) Cytokine gene expression in intact anagen rat hair follicles. Journal of Investigative Dermatology, 103, 715720. http://dx.doi.org/10.1111/1523-1747.ep12398584

[34] Mitsui, S., Ohuchi, A., Hotta, M., Tsuboi, R. and Ogawa, H. (1997) Genes for a range of growth factors and cyclindependent kinase inhibitors are expressed by isolated human hair follicles. British Journal of Dermatology, 137, 693-698.

http://dx.doi.org/10.1111/j.1365-2133.1997.tb01103.x

[35] Dafforn, A., Chen, P., Deng, G., Herrler, M., Iglehart, D.,
Koritala, S., et al. (2004) Linear mRNA amplification from as little as $5 \mathrm{ng}$ total RNA for global gene expression analysis. Biotechniques, 37, 854-857.

[36] Patel, O.V., Suchyta, S.P., Sipkovsky, S.S., Yao, J., Ireland, J.J., Coussens, P.M., et al. (2005) Validation and application of a high fidelity mRNA linear amplification procedure for profiling gene expression. Veterinary Immunology and Immunopathology, 105, 331-342. http://dx.doi.org/10.1016/j.vetimm.2005.02.018

[37] Brash, A.R., Boeglin, W.E. and Chang, M.S. (1997) Discovery of a second 15S-lipoxygenase in humans. Proceedings of the National Academy of Sciences USA, 94, 6148-6152.

[38] Nallur, G., Luo, C., Fang, L., Cooley, S., Dave, V., Lambert, J., et al. (2001) Signal amplification by rolling circle amplification on DNA microarrays. Nucleic Acids Research, 29, E118.

http://dx.doi.org/10.1093/nar/29.23.e118

[39] Che, S. and Ginsberg, S.D. (2004) Amplification of RNA transcripts using terminal continuation. Laboratory Investigation, 84, 131-137. http://dx.doi.org/10.1038/labinvest.3700005

[40] Dumur, C.I., Garrett, C.T., Archer, K.J., Nasim, S., Wilkinson, D.S. and Ferreira-Gonzalez, A. (2004) Evaluation of a linear amplification method for small samples used on high-density oligonucleotide microarray analysis. Analytical Biochemistry, 331, 314-321. http://dx.doi.org/10.1016/j.ab.2004.03.040

[41] Karsten, S.L., Van Deerlin, V.M., Sabatti, C., Gill, L.H. and Geschwind, D.H. (2002) An evaluation of tyramide signal amplification and archived fixed and frozen tissue in microarray gene expression analysis. Nucleic Acids Research, 30, E4. http://dx.doi.org/10.1093/nar/30.2.e4

[42] Auer, H., Lyianarachchi, S., Newsom, D., Klisovic, M.I., Marcucci, G. and Kornacker, K. (2003) Chipping away at the chip bias: RNA degradation in microarray analysis. Nature Genetics, 35, 292-293. http://dx.doi.org/10.1038/ng1203-292

[43] Imbeaud, S., Graudens, E., Boulanger, V., Barlet, X., Zaborski, P., Eveno, E., et al. (2005) Towards standardization of RNA quality assessment using user-independent classifiers of microcapillary electrophoresis traces. $\mathrm{Nu}$ cleic Acids Research, 33, e56. http://dx.doi.org/10.1093/nar/gni054

[44] Dash, A., Maine, I.P., Varambally, S., Shen, R., Chinnaiyan, A.M. and Rubin, M.A. (2002) Changes in differenttial gene expression because of warm ischemia time of radical prostatectomy specimens. American Journal of Pathology, 161, 1743-1748.

http://dx.doi.org/10.1016/S0002-9440(10)64451-3

[45] Dondrup, M., Hüser, A.T., Mertens, D. and Goesmann, A. (2009) An evaluation framework for statistical tests on microarray data. Journal of Biotechnology, 140, 18-26. http://dx.doi.org/10.1016/j.jbiotec.2009.01.009

[46] Sato, F., Tsuchiya, S., Terasawa, K. and Tsujimoto, G. (2009) Intra-platform repeatability and inter-platform comparability of microRNA microarray technology. PLoS One, 4, e5540.

http://dx.doi.org/10.1371/journal.pone.0005540 
[47] Bailey, K., Xia, Y., Ward, W.O., Knapp, G., Mo, J., Mumford, J.L., et al. (2009) Global gene expression profiling of hyperkeratotic skin lesions from inner Mongolians chronically exposed to arsenic. Toxicologic Pathology, 37, 849-859.

http://dx.doi.org/10.1177/0192623309351725
[48] Yin, Y., Li, W., Son, Y.O., Sun, L., Lu, J., Kim, D., et al. (2013) Quercitrin protects skin from UVB-induced oxidative damage. Toxicology and Applied Pharmacology, 269, 89-99. http://dx.doi.org/10.1016/j.taap.2013.03.015

\section{LIST OF ABBREVIATIONS}

JAXA: Japan Aerospace Exploration Agency

ISS: International Space Station

PCA: Principal Component Analysis

GEO: Gene Expression Omnibus

RIN: RNA Integrity Number 